\title{
EL MAL, LA LIBERTAD Y PINOCHET
}

\section{EVIL, LIBERTY AND PINOCHET}

\author{
ANDRES ESTEFANE*, LUIS THIELEMANN**
}

Resumen: Centrándose en la polémica que siguió a la clausura de la muestra "Hijos de la Libertad. 200 años de Independencia" del Museo Histórico Nacional de Chile, este artículo analiza dos problemas centrales en el abordaje del pasado reciente chileno: la pulsión de representar al dictador Augusto Pinochet como encarnación absoluta del mal y la imposibilidad de que el mismo Pinochet y su régimen puedan tener una vinculación no oposicional con el sentido actual de la idea de libertad. Revisando los desafíos abiertos por la problemática representación de la "memoria del dictador", sostenemos que esta polémica es síntoma de un proceso mayor: el agotamiento del discurso de la "transición a la democracia" como marco hegemónico para explicar y aproximarse al pasado reciente. Explorando el agrietamiento de dicho discurso, proponemos que este episodio abre la posibilidad para la emergencia de un revisionismo historiográfico orientado a superar el binarismo pinochetismo/anti-pinochetismo que todavía constriñe el estudio de la trayectoria política chilena de las últimas décadas.

Palabras Clave: Pinochet, Dictadura, mal, libertad, revisionismo historiográfico.

Aвstract: Focusing on the controversy after the closing of the exhibition "Children of Freedom. 200 Years of Independence" at the Chilean National History Museum, this article reviews two problems linked to the discussion of Chile's recent past: the drive to represent dictator Augusto Pinochet as evil incarnate and the impossibility of viewing Pinochet and his regime as other than opposed to a current understanding of the idea of freedom. By analyzing the challenges posed by this problematic representation of the "memory of the dictator", we argue that this controversy is symptomatic of a larger process: the exhaustion of the "transition to democracy" discourse as a hegemonic framework used to explain and confront the recent past. By exploring the fragmentation of this discourse, we propose that this episode opens up new paths for the advancement of

* Doctor en Historia. Director del Centro de Estudios de Historia Política de la Universidad Adolfo Ibáñez, Santiago, Chile. Correo electrónico: andres.estefane@uai.cl. Orcid: https://orcid.org/00000002-8216-4652.

** Doctor en Historia. Profesor asistente de la Escuela de Historia de la Universidad Finis Terrae, Santiago, Chile. Investigador Postdoctoral, International Institute of Social History, Ámsterdam, Países Bajos. Correo electrónico: luisthielemann@gmail.com. https://orcid.org/0000-0003-4666-2491. 
a revisionist historiography that would allow us to overcome the Pinochetism/Anti-Pinochetism binarism, which still constrains the study of Chile's recent political history.

KeYwords: Pinochet, Dictatorship, Evil, Freedom, Revisionist Historiography.

Recibido: 01.02.19. Aceptado: 03.04.2020.

E L ABRUPto CIERre de la muestra "Hijos de la Libertad. 200 años de Independencia” del Museo Histórico Nacional de Chile (MHN) dio paso a una polémica que visibilizó una vez más los nudos que determinan la relación de los chilenos con su historia reciente. En este escrito nos proponemos analizar dos de esos nudos. El primero se refiere a las consecuencias políticas de la pulsión por representar al dictador Augusto Pinochet como encarnación absoluta del mal. El segundo tiene que ver con la supuesta imposibilidad de que tanto Pinochet como su régimen puedan vincularse de forma no oposicional a la actual comprensión de la idea de libertad. Lo primero se configura como problema a partir de las reflexiones que siguieron a la clausura de la muestra, en particular desde aquellos intentos por disciplinar las representaciones de Pinochet como figura histórica, y de la Dictadura como experiencia fundacional. Lo segundo cobra forma a partir del encuadre que llevó al Ministerio de las Culturas, las Artes y el Patrimonio a decretar la censura de la exhibición, que al menos en tanto gesto público terminó validando la impresión de que vincular a Pinochet con la idea de libertad era una opción discursiva insostenible para una institución cultural gubernamental.

En términos gruesos, la polémica no hizo sino actualizar un dilema crucial en sociedades post-conflicto, pero que en Chile se ha esquivado de manera persistente: la pregunta por el lugar de los perpetradores de violaciones a los derechos humanos en la vida cotidiana y en las representaciones públicas del pasado reciente. Si parte importante del trabajo de procesamiento colectivo de la estela dejada por la violencia política estatal se ha centrado en el reconocimiento de las víctimas, la recuperación de sus memorias y la lucha simultánea por justicia y reparación, no se detectan avances similares en el abordaje de los dilemas ético-políticos, por no mencionar los judiciales, asociados a la presencia pública y simbólica de los responsables de dichas violaciones. El problema resulta particularmente delicado en el caso chileno, donde la cultura política posdictatorial ha tendido a ralentizar -cuando no obstruir- avances sustantivos en materias de verdad y justicia, abrigando incluso derivas negacionistas. El peso discursivo de los simpatizantes de la Dictadura, sumado el efecto político y jurídico 
de los "pactos de silencio" entre responsables y cómplices de violaciones a derechos humanos, configuran un cuadro predeciblemente hostil a las demandas de juicio y castigo de parte de las víctimas y sus familiares, y que simultáneamente ha contribuido a diferir el debate sobre la forma en que una comunidad política puede resolver los dilemas asociados a la presencia de estos perpetradores en la vida cotidiana, en las instituciones políticas, y en la elaboración pública de la memoria colectiva ${ }^{1}$.

En esta intervención nos proponemos ahondar en las consecuencias políticas e historiográficas de tales dilemas, pero no desde el punto de vista de los silencios u omisiones transicionales, sino más bien desde los atajos discursivos e inercias interpretativas derivadas de lo opuesto, esto es, de la saturación de la imagen del dictador devenido perpetrador absoluto, cuestión solo posible tras la deformación monstruosa de su agencia y su individualización como punto de convergencia de todo el horror dictatorial. Tal como quedó en evidencia a lo largo del debate que siguió al cierre de la muestra "Hijos de la Libertad", tanto la interpretación de Pinochet como la de su régimen parecen custodiadas por un férreo consenso que tiene su punto de origen y cierre en el binarismo pinochetismo/antipinochetismo. Si bien esta polaridad resultó útil como mapa de campo para la primera fase transicional, su asimilación incuestionada la instaló como frontera infranqueable para dirimir lo decible e indecible respecto al pasado reciente, reduciendo así las interpretaciones sobre la Dictadura a un esquema simplista de considerable efectividad como posicionamiento moral, pero de bajo rendimiento para el estudio racional de las fases, las tensiones y la densa red de complicidades que hicieron posible la materialización del proyecto del régimen más allá del factor Pinochet.

\footnotetext{
${ }^{1}$ El trabajo desarrollado por las académicas Daniela Jara y Carolina Aguilera es una importante excepción dentro de la escasa reflexión en torno a los dilemas políticos y extra-legales recién descritos. Ambas fueron editoras de la publicación Pasados inquietos. Los desafíos de la memoria pública de los perpetradores de violaciones a los DD.HH. y crímenes de lesa humanidad en Argentina y Alemania, resultado de un seminario internacional organizado en diciembre de 2016 en el Museo de la Memoria y los Derechos Humanos de Santiago; véase en particular la introducción a dicho trabajo (Jara y Aguilera, 2017, pp. 8-15). Investigaciones recientes, como The Wars inside Chile's Barracks. Remembering Military Service under Pinochet del historiador Leith Passmore (2017), han expandido la complejidad de estos dilemas poniendo en tensión los límites de las categorías "víctima” y "represor". Ese es el foco de su revisión de la experiencia de aquellos jóvenes conscriptos que durante la Dictadura se vieron involucrados en el engranaje institucional de abusos y violaciones del Ejército de Chile mientras cumplían el servicio militar. Indagando en las secuelas psicológicas y físicas que dejó en ellos el paso por cuarteles, regimientos y centros de detención y tortura (donde les cupo ser agentes y también sujetos de vejaciones), Passmore explora la forma en que estas experiencias activan la doble y compleja condición de víctima y perpetrador en un mismo ser humano, iluminando una de las zonas grises y más incómodas dentro de la política de la memoria de la Transición.
} 
Pero dicha saturación, sostenemos, no solo ha determinado las fronteras discursivas para hablar de la Dictadura, sino también el reconocimiento de las formas en que dicho régimen logra crearse y recrearse bajo las coordenadas que han sostenido el ordenamiento democrático. Es aquí donde emerge la segunda arista de la polémica, manifestada en la imposibilidad de tolerar lecturas que visibilicen cualquier rastro de continuidad entre la Dictadura como proyecto histórico y la trama valórica y política de la democracia parida por ese régimen. No es menor que entre todas las continuidades posibles, esta controversia estalle por el que quizá sea el concepto más controvertido como significante de época, el de libertad, usualmente visado como componente exclusivo del ecosistema democrático y naturalmente reñido con el encuadre autoritario. Lo que hizo la muestra, sin embargo, fue tensionar la lógica de esa disposición al mostrar -con un simple gesto empírico- que Pinochet y su dictadura promovieron una comprensión particular de libertad, y que ese uso no tenía por qué estar fuera del esfuerzo de reconstrucción de la historia del concepto; y lo que hizo la polémica, a su vez, fue demostrar que tanto el sistema cultural como el político chilenos no estaban dispuestos a tolerar este recordatorio impertinente, menos si ese recordatorio abría la puerta a la pregunta por la familiaridad entre la idea de libertad sancionada por la Dictadura y la forma concreta en que esa libertad se ha ejercido en plena democracia. Se trata, es cierto, de una pregunta incómoda, pues obliga a visibilizar las complicidades y complacencias que han sostenido los vínculos sustantivos entre el Chile previo y posterior al 5 de octubre de $1988^{2}$.

En esos términos, sostenemos que la polémica en torno a la muestra "Hijos de la Libertad" constituye un espacio productivo para pensar el agotamiento del discurso político de la "transición a la democracia" como marco hegemónico para explicar y representar el pasado reciente, sobre todo en aquellas franjas del espacio público antes controladas por los tribunos de la transición ${ }^{3}$. En esa misma línea, y explorando la forma en que este episodio desnuda el agrietamiento de dicho consenso, reconocemos aquí la apertura

\footnotetext{
${ }^{2}$ En Civil Obedience. Complicity and Complacency in Chile since Pinochet, Michael J. Lazzara (2018) estudia esta otra zona gris de la experiencia dictatorial, revisando el protagonismo de civiles que en su minuto colaboraron con la institucionalización del régimen y posteriormente, ya en democracia, contribuyeron a la mantención de su legado.

${ }^{3}$ Aludimos aquí a la existencia de "franjas del espacio público" subordinadas a un solo tipo de consenso para reconocer la pluralidad de relatos y escenarios que integran el paisaje político y social postautoritario chileno. Sin desconocer la fuerza determinante de ese consenso, corresponde también relevar la existencia de franjas definidas en oposición, prescindencia o rebeldía a esa hegemonía. Para conocer un trabajo reciente que apuesta por el reconocimiento de la pluralidad de experiencias transicionales, ver Ponce, Pérez y Acevedo (2018).
} 
de un flanco favorable a la emergencia de un revisionismo historiográfico dispuesto a superar el binarismo pinochetismo/anti-pinochetismo que todavía sigue encamisando el estudio de las últimas cinco décadas de la trayectoria política chilena.

En lo que sigue revisamos, primero, la fisonomía del discurso que en medio de la polémica situó a Augusto Pinochet como filtro de significación de todos los males del pasado reciente; tras ello, abordamos la vocación fiscalizadora y censora del consenso dominante en lo referido a la representación de la Dictadura, evaluando las implicancias de la configuración de un horizonte revisionista; acto seguido, sometemos a crítica histórica la supuesta incompatibilidad entre Pinochet y la idea de libertad -en la misma clave sostenida por los críticos de la muestra "Hijos de la Libertad", esto es, asumiendo la imposibilidad de ver al dictador en un panteón libertario-, y para ello rastreamos los vínculos entre las definiciones que la propia Dictadura (y el propio Pinochet) elaboraron sobre este concepto, así como la forma en que esas definiciones se actualizan en el Chile contemporáneo; concluyendo, se exploran las principales contradicciones y vacíos que han ido agrietando el otrora formidable discurso histórico de la Transición, viendo en ellos posibilidades para la configuración de una historiografía no tutelada por ese consenso.

\section{EL MAL Y PINOCHET}

Cuando sostenemos la caducidad del discurso histórico de la Transición, aludimos a la creciente ineficacia de los consensos históricos vigentes para ordenar las formas en que los intelectuales y capas mayoritarias de la sociedad se aproximan al pasado reciente. En específico, hacemos referencia a la representación de Pinochet como origen y agente último de todos los males atribuibles a la Dictadura, y también a su aparición como factor explicativo de la fisonomía del Chile actual ${ }^{4}$. De esa concepción infernal o catastrófica del hecho llamado Pinochet, por ejemplo, derivaría la imposibilidad de reconocer al dictador entre aquellas voces que a lo largo de la historia

\footnotetext{
${ }^{4}$ Sin desconocer la gravitación individual de Pinochet, Carlos Hunneus advierte los riesgos de explicar el régimen a partir de su figura, pues ello instala un reduccionismo que desatiende la complejidad política del momento. La Dictadura, según Hunneus (2016), tuvo al menos un dimensión coercitiva (la violencia estatal y las violaciones a los derechos humanos), una dimensión económica (encarnada con la institucionalidad neoliberal) y una personal (atada a la figura del dictador), y cualquier aproximación debe atenerse a la integración de ellas (Hunneus, 2016, pp. 60-79).
} 
chilena hicieron pública propaganda de ideas de libertad, tal como quedó en evidencia a lo largo de la polémica.

Durante el debate que siguió a la clausura de la muestra del MHN, en particular entre quienes sostuvieron posiciones críticas cuestionando la pertinencia de su guion, resaltaron argumentos que asociaron a Pinochet a la imagen del monstruo (Basaure, 2018 y 2018b) y otros que elevaron la Dictadura a la condición de evento catastrófico (Joignant, 2018) ${ }^{5}$. Por ende, la maldad de Pinochet y el inmenso daño generado por la Dictadura serían irrepresentables. De ahí que cualquier intento por ubicar al dictador como parte del panteón libertario local solo podía deberse a un disparate museográfico, a una falta de tacto político o a una solapada operación de negacionismo $^{6}$. De esa forma, lejos de explicar el violento proceso político que cruzó el período 1970-1993 y entender los resortes del proyecto histórico elevado durante ese mismo proceso, la Dictadura es allanada en la forma del mal absoluto, en categorías de barbarie que por su misma inmensidad serían indescifrables?

De la vieja "teoría de los dos demonios", aquella en que se igualaba la violencia golpista con la ejercida con anterioridad por los revolucionarios, y que tenía por fin justificar las dictaduras en la necesidad de restaurar un orden asediado por la acción de actores radicalizados, pasamos entonces a un nuevo encuadre, definido por lo que llamaremos aquí la "teoría del demonio único". En esta nueva versión, el dictador se dibuja como un factótum enfrentado a una sociedad unificada en una moral anti-autoritaria, una sociedad que, abrigada en un profundo humanismo, parece incapaz de superar el legado de un monstruo que escapa a todo esfuerzo de inte-

${ }^{5}$ La presencia de la idea de "catástrofe" en la reflexión local se afirma en la aparición de la traducción del trabajo de Henry Rousso, La última catástrofe. La historia, el presente, lo contemporáneo (2018 [2012]). Conviene no perder de vista la pertinencia de otros intentos, como el de Traverso (2012 [2011]), que apuntan a explicar y categorizar con toda la precisión posible las violencias del siglo XX, alejándose del allanamiento al que empujan rótulos como "mal absoluto" o "catástrofe", y reivindicando la comprensión del fenómeno mediante la revisión de sus raíces históricas y coyunturas definitorias.

${ }^{6}$ Para comprender el objetivo del ejercicio planteado por el MHN y calibrar así la postura de sus críticos, conviene revisar el catálogo de la muestra (Museo Histórico Nacional, 2018), en particular los textos de los especialistas que abordaron las dimensiones más sensibles de la recepción y significados de la idea de libertad (Arriagada y Silva, 2018 y Alegría, 2018).

${ }^{7}$ La periodización 1970-1993 para referirse al proceso político chileno reciente permite reposicionar la complejidad y multidimensionalidad de la crisis del orden del Estado. Dicho período se abre con el ascenso de un gobierno de vocación de reforma radical y socialista, incluye la restauración autoritaria de 1973, la refundación institucional de 1980 y su realización y normalización en "democracia protegida" entre 1988 y 1993, cerrando con el aniquilamiento de la izquierda armada, el afianzamiento de las lógicas de consenso en la administración del poder político y con la realización de elecciones presidenciales regulares en diciembre de 1993. 
ligibilidad y comprensión histórica. A diferencia de la "teoría de los dos demonios", que acudía al pasado revolucionario para ecualizar y purificar la violencia contrarrevolucionaria que le siguió, la teoría del demonio único se proyecta sobre un presente que al desplegarse pretende amarrar y cerrar el futuro. Con esto se buscarían al menos dos objetivos. Por una parte, exculpar a los actores del presente de su participación en la permanencia y reproducción del modelo de orden y sociedad resultante de la acción del demonio único (que en su monstruosidad, dicho sea de paso, sigue emergiendo como una frontera irreductible). Por otra, elevar al monstruo como una amenaza latente, imperecedera, activa incluso después de su desaparición física, para desactivar así cualquier tipo de disenso en torno a la necesidad histórica de preservar su legado.

Conviene detenerse en el peso semántico de esa representación para entender su operatividad. Un monstruo político es un ser anómalo, su origen y presencia son misteriosas, y ésa es la clave para entender su lugar moralizante en la cultura ${ }^{8}$. Ahí está el origen del problema: de una representación monstruosa necesariamente destila una visión mítica -no histórica- del terror que ese monstruo genera. En esa deformación fantástica de quien ejerció el mal se va deteriorando la comprensión de lo que ese agente efectivamente pudo realizar, así como de la infraestructura social y legal que sostuvo su accionar. A la hora del balance, la gran damnificada es la comprensión histórica de ese legado. Si sabemos que los monstruos no existen, ¿qué hacemos con el terror que se les atribuye?

En este sentido, podríamos decir que la restauración democrática, en las formas que adoptó desde 1990, necesitaba un "gran satán", un "monstruo" culpable y lo suficientemente gravitante como para consumir en su propia figura todo el daño que hoy neurotiza las memorias de los chilenos. Lo delicado es que en esta historia de un mal personalizado se pierden todas las trazas de aquellas historias mínimas e incómodas que todavía parecen inconfesables: las de vecinos delatores y proletarios enrolados en la DINA y la CNI (Rebolledo, 2014), de políticos conversos y anestesiados en los bálsamos de la plutofilia (Lazzara, 2018); se pierde también el espectro de esa clase media golpista luego devenida demócrata ferviente (Casals, 2018

\footnotetext{
${ }^{8}$ Benjamín Vicuña Mackenna fue un notable referente local en el uso del tropo de la monstruosidad como instrumento de intervención política. Esa fue la enseña que reunió sus dramáticos perfiles de figuras como Catalina de los Ríos y Lisperguer, Luis de Zañartu, Miguel José Cambiaso y tantos otros que sirvieron a su propósito de tornar la biografía en una sofisticada herramienta para animar las controversias políticas que debían sostener la vida civil (Vicuña, 2008; Estefane, 2013). Para una aproximación a la representación internacional de Pinochet en esta misma clave, véase Gárate (2015).
} 
y 2019) como también el espectro incómodo de los pobladores que votaron convencidos por el Sí el 5 de octubre de 1988. En ese encuadre, el único que debería responder por la violencia es Pinochet, pues su vertical control sobre la fuerza bruta emerge como la única explicación para que ocurriera lo que efectivamente aconteció. Ese gran otro, el dictador capaz de deglutir en su organismo a la extendida parentela de asesinos y cómplices que mantuvo en funcionamiento la sala de máquinas de la Dictadura, sirvió entonces para unificar a ese Chile que había aceptado el discurso de una ciudadanía moderna, pacífica y democrática.

En varios sentidos, la discusión que siguió al cierre de la muestra generó las condiciones para percibir los últimos estertores de esa visión vieja y simple del pasado reciente, apuntalada por la hegemonía de los gobiernos de la Concertación y reactivada en la propaganda electoral de los rituales eleccionarios, ésa que reduce el campo político a la polaridad pinochetismo/anti-pinochetismo. En la urgencia de reforzar la democracia y conjurar el peligro de la regresión autoritaria, no parecen haber existido condiciones para reconocer grados o matices, ni para hacer una genealogía de las distintas fuerzas que componían cada uno de estos campos. Ese binarismo proyectó su inercia a todas las formas adoptadas por la democracia post-autoritaria y es ahí donde reposó parte importante de su función disciplinante y preventiva: al simplificar la Dictadura y lo decible sobre ella, desactivó toda rebeldía respecto a la legitimación democrática del modelo que instauró.

Si bien la polémica ilustró que ese mecanismo tiene todavía relativo rendimiento, también dejó entrever que su capacidad de disciplinamiento y prevención se han deteriorado con la misma profundidad que la coalición política que lo sostuvo. Aquí debemos recordar el hecho-síntoma: la indignación en torno a la inclusión de Pinochet en la trayectoria de los usos de la palabra libertad da paso a una discusión sobre cómo se debía lidiar con su existencia histórica. Algunos polemistas indicaron que como sociedad solo había dos alternativas: o se ignoraba a Pinochet o se le ubicaba en la jurisdicción del horror (Basaure, 2018a). Y entre ambas, no cabría más opción que la segunda, reforzando así el espectro de ese monstruo inabarcable construido desde la década de 1990 . No hay que estirar en demasía el argumento para entender que este encuadre no es más que una reposición de la lógica binaria de la transición democrática. El monstruo, el demonio único, el horror irrepresentable, entre otras, son todas formas de denominar el hecho Dictadura esquivando el trabajo de explicarla. Es la anomalía que se explica en el pozo oscuro de la teoría que sostiene su nombre. Poco de historia y mucho de leyenda hay en tal propuesta. 
Nuestra intervención en la polémica se centró no tanto en negar esa polaridad, sino más bien en superarla abriendo otra ruta interpretativa. Pero ello implica asumir la necesidad de hablar de un Pinochet real, sacándolo de la jurisdicción de la infamia y el horror -la principal razón para sostener el argumento de irrepresentabilidad- y procesarlo históricamente empleando las palabras y las herramientas analíticas que ofrece la razón (Estefane y Thielemann, 2018a y 2018b). En el rechazo tanto a la posibilidad de ignorarlo como a la tentación de convertirlo en la encarnación irrepresentable del mal, cobra forma una ruta no prevista o virtualmente imposible dentro del escenario dual.

Quizá no haya una muestra más clara de la traza concertacionista en la "teoría del demonio único" que la reacción a esta propuesta. El solo hecho de sugerir el rescate de un Pinochet real y no deformado, para desde ahí elaborar una interpretación compleja de la Dictadura, fue inmediatamente procesado y reducido a la obsesión de anti-pinochetistas vocalizando posturas pinochetistas (Basaure, 2018b). Puesto de otro modo, cualquier intento por ir más allá de Pinochet para integrarlo en un análisis que lo haga parte de la Dictadura, y no su alfa y omega, es ubicado en las filas de la parcialidad del régimen, en tanto esa interpretación cobijaría una oblicua defensa.

Si quisiéramos ser benevolentes con esa operación, viendo en ella ciertos fines morales o incluso una preocupación genuina por las implicancias políticas de esta forma de revisionismo, el único punto digno de consideración sería el temor de que una interpretación compleja de la Dictadura pueda terminar relativizando las violaciones a los derechos humanos. Si evaluamos la matriz que sostiene el discurso de la monstruosidad, él solo puede existir exacerbando las trazas de violencia del régimen. Independientemente de que dicha violencia se concentre en Pinochet o se diluya en la complicidad de una coreografía más amplia de actores, la barbarie de la violencia de Estado es el único resorte al que esa representación maligna puede echar mano. Visto así el asunto, ¿es cierto que la revisión del discurso binario abre la puerta a la relativización de las violaciones a los derechos humanos o, en el peor de los escenarios, a la rehabilitación del negacionismo? Nada más lejos de la realidad.

Si hay algo en lo que falla el recurso a la exacerbación de la violencia como sostén de la idea de monstruosidad, es en convertir a esa violencia en un hecho absolutamente alienado de su función histórica dentro del proceso de la Dictadura. En breve, es negar la función política de esa violencia. Cuando la tortura y la denigración física del enemigo es reducida a las fron- 
teras del cuerpo y a un simple gesto de negación de la humanidad del otro, desconocemos que la sumatoria de esas acciones cumplió también un papel central en la creación de condiciones sociales y políticas para la materialización del proyecto histórico del régimen. Representar la violencia como si esa violencia constituyera un guión histórico separado de los otros guiones dictatoriales; asumirla como una cuestión sin fines reproductivos en los propósitos refundacionales de la Dictadura, implica nuevamente aceptar aquella narración limitada que convierte todo en un llano de barbarie y que desgaja el lapso 1970-1990 del lapso 1980-2019. Para manifestarlo en términos más claros: una visión revisionista de la dictadura no relativiza la violencia de Estado, no niega la barbarie, ni desatiende la herida sangrante creada por la impunidad. Al contrario, rehabilita esa violencia, la reconoce en su estatus político y por lo mismo la integra como parte de la génesis del Chile actual.

Aquí conviene volver, una vez más, al episodio que enciende todo este debate. Una protesta "twittera" que viraliza una foto tomada por una ciudadana que denuncia la muestra del MHN por asociar a Pinochet con la idea de libertad. Las medidas institucionales son tan irreflexivas como mediáticas y derivan en la expulsión del director del museo y la censura de la exposición. Queda así claro que hay límites para el trato analítico de Pinochet. El hecho, sin embargo, no es solo parte de su contexto inmediato, sino también expresión de una historia más larga. Es al menos desde la segunda mitad de la década de 1980, cuando se fue construyendo aquel relato que separó la obra económica neoliberal de su costo en horror, muerte y desigualdad; y fue también en ese lapso que se comenzó a opacar la historia política real de la Dictadura para reemplazarla por la leyenda de una catástrofe pródiga en mártires, héroes cívicos y demócratas de papel y lápiz. El discurso sobre el período 1973-1990 pasó entonces de la crítica a la Dictadura y al orden social pinochetista a la centralidad absoluta del dictador en tanto factótum. De ahí que el NO de octubre de 1988 haya sido presentado por sus propios promotores y desde un principio como un NO contra Pinochet, nunca contra su orden. De ahí que ese NO haya sido visto como una sofisticada muestra de civilidad contra una maldad delimitada al dictador y con suerte compartida con otros entes abstractos, como la DINA, la CNI y "los asesinos" que hicieron posible el genocidio cívico-militar. Son todas formas de lo mismo. Distintas formas que nos inmunizan de los relieves específicos, de los nombres propios, de las clases sociales y de las historias incómodas que jalonaron el día a día del terror antihumano. Se erigió así una idea de tiempo, país y sociedad aplanada en esa argamasa que es el 
rótulo Dictadura, y cuya única forma era Pinochet. Cualquier intento de entrar a conocer su forma real, sus fuerzas profundas, su apoyo en las masas y la cotidianeidad que desarma a los héroes para mostrar a los humanos, sigue siendo catalogado de revisionismo o de entreguismo a las fuerzas de derechas. De ese modo es que busca desacreditar a toda porfía historiográfica que se muestre desleal con los vencedores de 1988 y 1990.

En consecuencia, con la sacralización del binarismo pinochetismo/antipinochetismo, que fue uno de los paraderos de este debate, se fijó no solo una visión simplificada y a-histórica de la dictadura, sino también una polaridad funcional a la democracia protegida y binominal que dicho régimen legó (Moulian, 1997; Ruiz, 2015). Si hacemos memoria, el antipinochetismo cobijaba en sus filas a todos los que quisieran serlo. El pinochetismo, en cambio, era un pecado. De nuevo: en ese encuadre no se aceptaron matices. La democracia fue así purificada de su mancha fundacional, representada por la firma de Pinochet en la Constitución de 1980. De esta forma se podía administrar la historia como botín de guerra compartido entre los vencedores de 1988 y 1990. Y también entre los orgullosos taumaturgos de la nueva firma constitucional de 2005 (Atria, 2013).

Tal vez eso fue lo que no entendió ni el mismo Pinochet aquella noche del 5 de octubre de 1988. Es conocida su perplejidad en ese momento definitorio. Probablemente Pinochet pasó por alto que la realización de la libertad pinochetista necesariamente implicaba que él dejara el poder. La forma Dictadura se superó en la forma "democracia protegida", y la historia de la misma fue procesada en un relato electoralmente rentable y que contenía importantes dispositivos de reactualización. Así, la política quedó suspendida en el mismo lugar en que estaba en 1990, pues a los administradores de la libertad pinochetista les convenía ese pasado acordado en el bienio 1988-1989.

El problema con la demonización de Pinochet es que mediante dicho relato se desconoce la ubicuidad contemporánea del régimen. $\mathrm{Al}$ acordonar la culpa en Pinochet y al abstraer la forma concreta del terrorismo de Estado en conceptos imprecisos y espectaculares como "genocidio", no hacemos más que aceptar que la leyenda se imponga sobre la historia. De esa forma se facilita el desconocer que la libertad de los años 90 y la de hoy es la libertad que deseó explícitamente el régimen. Una libertad prefigurada, escrita e institucionalizada con éxito. ¿Importa que Pinochet haya sido un demonio o un sádico? Importa para quienes creen que el problema se reduce a Pinochet. Lo que parece relevante para la vida concreta es que el régimen que él lideró a partir de 1973 se propuso montar una democracia 
no muy distinta de la que actualmente existe, una democracia inspirada en una definición de libertad que hoy tiene la capacidad de limitar eficazmente nuestras discusiones en materia educacional, en materias de consumo, en la regulación del trabajo, en la comprensión del emprendimiento, en la defensa de la propiedad. Visto así el asunto, cuesta entender el rechazo a ver a Pinochet en un panteón libertario cuando la única forma en que el marco legal y no pocas franjas de la sociedad chilena asumen la libertad es la forma que la Dictadura proyectó sobre el presente.

\section{LA LIBERTAD Y PINOCHET}

Hacia 1982, la actuación del "poder constituyente" de la Junta Militar y sus fuerzas había logrado fijar los cimientos del orden neoliberal en Chile. La crisis económica de ese año, y las protestas que le siguieron, pusieron presión sobre el edificio dictatorial y generaron retrocesos tácticos en el itinerario programado por el régimen, pero sin alterar la estrategia de fondo. De ahí la importancia de revisar los discursos de Pinochet durante la "década creativa" de la Dictadura (1973-1983), dado que allí se hace evidente el carácter afirmativo de su posición política y de los hechos históricos que el régimen pudo proyectar más allá de la crisis económica (Taylor, 2006, pp. 53-98). Las palabras de Pinochet son inquietantes no tanto porque revelen una idea precisa de libertad, sino porque esa idea aparece explicada y promovida como un valor más profundo y significativo que la misma idea de democracia, la gran damnificada de la acción desestabilizadora del marxismo durante el siglo XX, según el oficialismo.

Eso al menos es lo que queda en evidencia en un libro que recopila distintos discursos y vocerías de Pinochet durante los años 1973 y 1983, publicado a modo de soporte ideológico de la nueva Constitución (Pinochet, 1983). En dicho texto se rescatan posiciones relativas al poder constituyente, a la forma de la democracia y, lo que nos interesa aquí, a la idea de libertad. Como veremos, la idea de libertad de Pinochet no parece distante, sino más bien cercana -inquietantemente cercana- a los valores dominantes en el consenso político en las décadas de la Transición.

Para Pinochet, y en general para el ideario de la Dictadura, la libertad era un valor que se había visto amenazado a lo largo del siglo XX, y tal hecho constituía una de las principales motivaciones para el golpe de Estado de 1973. La amenaza estaba en el hecho de que la expansión del poder del Estado durante el período desarrollista, vía impuestos o apropiación, im- 
pedía la actividad económica de los agentes privados. En julio de 1980, en una reunión con dirigentes sociales de base de la Región Metropolitana, Pinochet preguntaba " $¿$ Qué libertad significaba aquella democracia que, a lo largo de 35 años de aventura estatista, mantuvo al 22\% de los chilenos sumidos en la extrema miseria?" (Pinochet, 1983, p. 22). De esta forma, libertad y pobreza no son correspondientes en el discurso pinochetista, y es mediante dicha sugerencia que se busca disolver el argumento según el cual el golpe de Estado sería contrario a la libertad. Por el contrario, el golpe y la Dictadura se habían montado en defensa de aquella libertad que la democracia amenazaba, al ser el "caballo de Troya" del marxismo. El contraste también quedó claro en esa misma reunión, cuando volvía a preguntar:

¿Podría alguien sostener que durante el período de la mal llamada Unidad Popular existía en Chile la verdadera libertad? Sin duda que ello no es posible, porque debemos recordar que, día a día, el Estado asumía el control de diversos medios de producción y organizaciones sociales, ahogando la iniciativa y limitando, por tanto, la verdadera libertad. (Pinochet, 1983, p. 101)

La forma en que se concretó la amenaza marxista fue la intervención del Estado en la economía. Así, las tres décadas y medias de desarrollismo fueron abriendo las puertas a un avance del Estado sobre el individuo. En una clase magistral de Pinochet en la Universidad de Chile, en abril de 1979, se explicaría dicha fórmula:

En la misma medida en que el Estado asume el control de la actividad económica desaparece igualmente la libertad individual, que puede considerarse extinguida desde el momento en que el Estado controla el consumo. Evidencia de ello se encuentra en los regímenes que han abolido la propiedad y la iniciativa privada. (Pinochet, 1983, p. 135)

Así, el avance del Estado en la economía ahogaba la libertad individual, y su máxima expresión eran los Estados socialistas. Como repitió en varias intervenciones, fue la democracia liberal la que posibilitó ese tránsito en Chile, y de ese socavamiento se origina la catástrofe de 1973. En el discurso de conmemoración del sexto año de la Dictadura (1979), agregó:

La experiencia nos enseña que nuestra vieja democracia se prestó durante largo tiempo precisamente para que el estatismo económico-social y la demagogia política erosionaran en forma progresiva y constante la libertad real de los chilenos, especialmente en lo social, y que además 
retardara el progreso que nuestra Nación requería. Todo ello pavimentó el camino para que el totalitarismo marxista alcanzara el poder, momento en el cual fue ya una agresión al servicio de un imperialismo foráneo que estuvo a punto de abolir en Chile toda forma de libertad. (Pinochet, 1983, p. 21)

En ese mismo discurso Pinochet estableció la polaridad estratégica que orientaba su gobierno, y también el ordenamiento ideológico en que se basaba:

El único dilema verdadero y actual es, o volver a la vieja democracia que favorecía el totalitarismo, el socialismo estatista, la inseguridad, la subversión y la demagogia, o avanzar hacia una nueva democracia que favorezca establemente la libertad, la seguridad, el progreso y la justicia. (Pinochet, 1983, p. 100)

Así, la libertad según Pinochet no es su orden, que se plantea en todo momento como constituyente, es decir, de emergencia, sino una nueva fórmula democrática, la democracia protegida.

En el discurso con motivo del Día del Trabajo en 1981, el dictador insistirá en este encuadre, planteándola como alternativa a la propuesta opositora de retorno a la democracia liberal:

A los defensores de un sistema que pretende monopolizar el calificativo de democrático, y que nos atacan defendiendo la libertad, les digo que precisamente en este punto estamos de acuerdo: no somos enemigos de la libertad. Pero sí somos enemigos de una liberalidad ingenua y suicida, que basa sus posibilidades de sobrevivir en su capacidad para soportar y halagar a quienes proclaman que desean ser sus verdugos y que muchas veces han llegado a serlo. (Pinochet, 1983, p. 24)

Indudablemente resuenan aquí algunos resabios de la posición tercerista que el régimen quiso adoptar en el marco de la biporalidad de la Guerra Fría, esbozada tempranamente en el preámbulo de la "Declaración de Principios del Gobierno de Chile" (1974), cuando se toma distancia tanto de los modelos de inspiración socialista como del materialismo ciego de las "sociedades de consumo" (Pinochet, 2001 [1974]). Ello, sin embargo, terminará desdibujado con el triunfo de las fuerzas aperturistas y el predominio del monetarismo ortodoxo, primero, y el pragmático, después. Lo que queda claro es el esbozo de la separación entre política y sociedad, sentando el principio de que lo uno no debe intervenir sobre lo otro. La 
libertad queda así fuera de alcance no solo del marxismo, sino también de toda la política, en tanto cualquier amenaza a ese anillo de salubridad debe ser neutralizada por la fuerza, de ser necesario. Esta idea defensiva o proteccionista de la democracia, en pos de la libertad, es considerada parte de los "aprendizajes" que según Pinochet destilaban de la experiencia política previa a 1973, y se tornan evidentes en un discurso de 1977, en una reunión con la comisión constituyente: “(...) el gobierno de hoy está consciente de que no puede permitir ninguna posibilidad de volver a dejar infiltrar en nuestra institucionalidad a este adversario intrínsecamente perverso, pues de ser así, volvería a provocar el caos en Chile, y ahora para siempre" (Pinochet, 1983, pp. 15-16). La necesidad de preservar la libertad protegiendo a la democracia de la política -campo en el que el marxismo emerge como una especie de "cultura general"-, también se explica con claridad en la ya referida clase magistral en la Universidad de Chile (1979):

Toda sociedad se funda en cierto grado de consenso o unidad común en torno a determinados valores y objetivos básicos, que permiten su existencia como tal y su progreso hacia las metas que ellos suponen. Al mismo tiempo, toda sociedad humana lleva encerrada en sí misma un grado de discrepancia, cuya eliminación es el propósito que comparten por igual las tiranías de cualquier signo. Por el contrario, una sociedad que verdaderamente desee vivir en un régimen de libertad, debe ser capaz de hacer coexistir equilibradamente ambas realidades, unidad y discrepancia. En Chile, tal consenso mínimo desapareció como consecuencia del avance y posterior asunción al poder del marxismo soviético. (Pinochet, 1983, pp. 21-22)

Hasta el momento hemos visto que la idea de libertad en Pinochet está reñida con cualquier idea de política contingente o de reforma del Estado. La expulsión de la política de la administración del orden social -es decir, el destierro de la vieja idea de democracia existente hasta 1973- es lo que en definitiva haría posible la defensa de la libertad. Así entendida, la libertad ya no es cosa de la política, sino de la normalidad capitalista instituida formalmente a partir de 1980, y realizada en la democracia abierta desde 1988. Se instala así una idea de libertad atada al consumo en el mercado, y reforzada con la promesa del emprendimiento como iniciativa privada. Es una libertad definida por y para la consagración del capitalismo neoliberal, y que encuentra en la autonomía del individuo -emancipado en tanto consumidor, productor y trabajador- su principal espacio de reproducción (Eagleton-Pierce, 2016, p. 82; Martínez de Pisón, 1996, pp. 244245 ). Se trata de la materialización de lo señalado por Milton Friedman 
(2002 [1962]), en Capitalism and Freedom, cuando afirmó que "la libertad económica" era un "medio indispensable para la obtención de la libertad política” (p. 8, trad. propia).

En efecto, la reducción de la idea de libertad a la libertad de los individuos en el mercado es un tropo que aparece reiteradamente en las intervenciones oficiales durante la "década creativa". En la cuenta anual del gobierno de 1982, a propósito de la entrega de 10 mil títulos de propiedad "en el sector indígena", Pinochet afirmó estar sembrando "la semilla de la libertad" (Pinochet, 1983, p. 116). Quizá la versión más sofisticada de esta comprensión, y que reverbera con fuerza en la experiencia de los chilenos de la era OCDE, fue formulada en un pasaje del ya citado discurso de Pinochet a los dirigentes sociales de base de 1980 y que vale la pena citar íntegro:

Vivir en un sistema donde es posible seleccionar la educación de nuestros hijos; donde se puede elegir el medio de trabajo; donde la afiliación o desafiliación a una organización sindical son voluntarias; donde se reconoce la propiedad privada y se fomenta la libre iniciativa de los particulares en el campo económico, es disponer verdaderamente de la libertad. La idea de libertad va necesariamente unida a la ausencia de un Estado omnipotente e interventor. Una sociedad realmente libre es aquella en que este cumple el papel subsidiario que le corresponde dejando a los particulares un amplio campo para canalizar sus aspiraciones, lo cual redunda en beneficio de todos. Entendemos que una sociedad es realmente libre y auténticamente democrática cuando sus ciudadanos tienen derecho a ejercer su libertad diariamente, en cada una de las organizaciones sociales a que pertenecen. (Pinochet, 1983, p. 101)

Los paralelos con las definiciones vulgares de libertad difundidas con posterioridad por otros personeros del régimen se torna aquí crucial, toda vez que apuntalan la promesa de la "libre elección" en planos aparentemente tan disociados como el consumo, la previsión, la salud, la educación y la entretención. Se trata, en definitiva, de un salto histórico que amalgama libertad con individuación en la abundancia. Así al menos lo retrata Joaquín Lavín (1987) en Chile: revolución silenciosa, al reflexionar sobre la emergencia de la "sociedad de las opciones":

Los chilenos comienzan paulatinamente a vivir con muchas más opciones que en el pasado. La sociedad de 'esto o lo otro', con dos o tres alternativas como máximo, ha sido superada por una nueva sociedad de 'opciones múltiples', en que es posible elegir entre las más diversas posibilidades. Estábamos acostumbrados a jubilar en la Caja de Empleados 
Públicos, el Servicio de Seguro Social o la Caja de Empleados Particulares; a confiar nuestra salud al Servicio Nacional de Salud o al Servicio Médico Nacional; a estudiar en la Universidad de Chile, Católica o Técnica; a ver televisión en el canal 13, 11 o el 7. Hoy la situación es muy distinta: podemos jubilar en la Administradora de Fondos de Pensiones que elijamos, entre más de diez distintas; confiar nuestra salud al Instituto de Salud Previsional que queramos, de entre cerca de veinte; seguir estudios superiores en cualquiera de las veinticinco universidades o institutos profesionales públicos o privados; podemos elegir entre cinco canales de televisión en Santiago, cuatro de televisión por cable, mientras que un número creciente de familias está confeccionando su propia programación arrendando películas en cualquiera de los ochenta y siete clubes de video existentes en las principales ciudades del país (...). Vivimos en una sociedad 'desuniformada', en que la atención personalizada reemplaza a la estandarización y los 'trajes a la medida' desplazan a la producción masiva. Una dueña de casa que entraba a comprar al Almac en 1974, podía elegir entre 5.500 productos diferentes. Hoy su gama de alternativas se ha multiplicado por tres, alcanzando a 15.500 ítems distintos, considerando marcas, tamaños y envases diferentes. Hay una nueva generación de niños acostumbrados a optar, que ven la publicidad y toman sus propias pequeñas decisiones de compra sobre marcas de helado o de yogurt. (pp. 24-25 y 152-153)

En una entrevista con la revista Ercilla en 1980, Pinochet elaboró una definición en positivo de su idea de libertad, ya no en contraste con el pasado local o con la experiencia de los países socialistas del último cuarto del siglo pasado, sino centrada en sus posibilidades. Lo sugerente, tal como en el fragmento recién citado de Lavín, es que la libertad emerge como un ideal que va más allá de la propia Dictadura, o que en el mejor de los casos la Dictadura solo media, en espera de su realización plena en una nueva democracia:

(...) es nuestro propósito construir una sociedad basada en la libertad de los individuos y en la igualdad de oportunidades para todos, sin que exista otra distinción que las que provengan del esfuerzo y superación personal. Lo considero un deber al que no renunciaremos jamás, pues es la base de esa sociedad justa e integrada a la que aspiramos y en la cual hemos comprometido toda nuestra autoridad de gobierno. (Pinochet, 1983, p. 107)

La idea de libertad de Pinochet y su régimen está centrada y se realiza en el individuo, a través del consumo y el emprendimiento, y se materializa en 
la posibilidad de elegir el trabajo o la educación de los hijos, en pensionarse o recuperar la salud optando entre esta u otra institución, en la libertad para organizarse o no en instancias colectivas. Sin necesidad de hacer mucho esfuerzo, se torna evidente que las ideas de la Dictadura sobre las formas en que la libertad se concreta resultan perfectamente compatibles con la noción defendida desde hace décadas por la democracia representativa global (Zamora, 2019). En estas coordenadas, la crítica histórica muestra cuán complejo resulta afirmar que la trayectoria histórica del concepto de libertad en Chile aborrece de manera automática la imagen de Pinochet. $\mathrm{O}$ en reverso, desnuda qué es lo que realmente se pretende al declarar la imposibilidad de tal asociación: negar que la Transición asumió la opaca tarea de conducir el tránsito hacia la plena concreción de la idea de libertad promovida por el régimen de Pinochet. Visto así el problema, lejos de negar o ser contraste de la Dictadura, la Transición abrigó la forma superior y plena de la libertad promovida por el neoliberalismo.

\section{CONCLUSIÓN}

Lo expuesto no hace sino reinstalar la urgencia por superar la leyenda heroica según la cual la Dictadura chilena fue derrotada con un papel y un lápiz, desmontando así el mito de la liberación y el cambio abiertos desde 1990. Si el deber ciudadano de nuestro tiempo es aportar a la construcción de diques democráticos que anulen la repetición del terrorismo y la violencia antihumana que se apoderó de la política y la sociedad chilena en el largo final del siglo XX, entonces la tarea de quienes trabajan con el pasado es esclarecer las razones y condiciones de posibilidad de ese terror, establecer la forma real de la Dictadura e iluminarla en su incómoda complejidad.

¿Habrá llegado la hora de promover la legislación que previene el negacionismo o la apología de la violencia y el terrorismo de Estado? La experiencia contemporánea parece sugerir que ese tipo de leyes no impiden la masificación de dichos discursos. Más allá de las condenas retóricas o formales al pasado de violencia, y más allá de los intentos por cerrar la discusión sobre el pasado a fuerza de leyes, una sociedad como la chilena debería partir por abrirse a una explicación histórica que asuma los orígenes ciudadanos, cotidianos, corrientes e insoportablemente humanos del horror dictatorial, así como de aquellos resortes valóricos que hoy emparentan los días de la tiranía con los días de la democracia.

Eso, como hemos dicho, implica entender la Dictadura como una op- 
ción de masas, como una opción de aquellas bases sociales que la apoyaron incluso a conciencia del error que se cometía. Implica asumir que ese edificio se montó en nombre de ideas de libertad, de democracia, de economía y de política que hoy son hegemónicas y compartidas por importantes franjas de la población del país. La historia de esos sectores todavía no ha sido escrita y en ello el discurso transicional ha sido clave, obstruyendo ese crucial paso. A más de tres décadas del plebiscito de 1988, los debates en torno a la representación de la Dictadura como una planicie política y de Pinochet como factótum del mal, entregan pistas claras de la ruta a seguir para superar la retórica sobre el pasado que sostuvo la Transición. Solo así podremos desarmar y liberarnos de esa otra tiranía montada por aquellos administradores civiles que insisten en seguir dictando qué se puede decir y qué no del pasado reciente.

\section{REFERENCIAS}

Alegría, L. (2018). Crisis y resignificación de la idea de libertad en el Bicentenario. En Museo Histórico Nacional (2018). Hijos de la Libertad. 200 años de Independencia (Santiago: Servicio Nacional del Patrimonio Cultural). En línea: https://www.mhn.gob.cl/618/articles-85161_archivo_01.pdf

Arriagada, P. y Silva, B. (2018). Recepción del concepto de libertad en la historia de Chile. En Museo Histórico Nacional (2018). Hijos de la Libertad. 200 años de Independencia (Santiago: Servicio Nacional del Patrimonio Cultural). En línea: https://www.mhn.gob.cl/618/articles-85161_archivo_01.pdf

Atria, F. (2013). La Constitución tramposa. Santiago, Chile: Lom Ediciones

Basaure, M. (2018a, mayo 11). Pinochet y lo irrepresentable, El Desconcierto. Disponible en: http://www.eldesconcierto.cl/2018/05/11/pinochet-y-loirrepresentable/

Basaure, M. (2018b, mayo 24). La monstruosidad y Pinochet, El Desconcierto. Disponible en: http://www.eldesconcierto.cl/2018/05/24/la-monstruosidad-y-pinochet/

Casals, M. (2018). Estado, contrarrevolución y autoritarismo en la trayectoria política de la clase media profesional chilena. De la oposición a la Unidad Popular al fin de los Colegios Profesionales (1970-1981). Izquierdas 44, 91 113.

Casals, M. (2019). The Insurrection of the Middle Class. Social Mobilization and Counterrevolution during the Popular Unity Government, Chile, 19701973. Journal of Social History. En línea: https://doi.org/10.1093/jsh/shz110 Eagleton-Pierce, M. (2016). Freedom. Neoliberalism. The Key Concepts (pp. 8187). London \& New York, United Kingdom; United States: Routledge.

Estefane, A. (2013). Después de la sangre, la tinta. En Vicuña Mackenna, 
B. La Quintrala y otros malos de adentro (Selección y edición de Vicente Braithwaite, pp. 9-20). Santiago, Chile: Ediciones UDP.

Estefane, A. y Thielemann, L. (2018a). Sobre la necesidad ciudadana de recordar al Pinochet real, Red Seca, 15 de mayo, en línea, URL: http://www. redseca.cl/sobre-la-necesidad-ciudadana-de-recordar-al-pinochet-real/

Estefane, A. y Thielemann, L. (2018b). Afrontar una historia miserablemente humana, Red Seca, 30 de mayo, en línea, URL: http://www.redseca.cl/ afrontar-una-historia-miserablemente-humana/

Estefane, A., Olmedo, C. y Thielemann, L. (eds.) (2019). 1988-1968: De la Transición al largo '68 en Chile. Santiago, Chile: Ariadna Ediciones.

Friedman, M. (2002 [1962]). Capitalism and Freedom. Chicago, United States: University of Chicago Press.

Gárate, M. (2015). El nacimiento de un monstruo. El Golpe de Estado en Chile y la imagen de Augusto Pinochet a través de las caricaturas de la prensa escrita francesa (1973-1990). Caravelle 104, 87-114.

Hunneus, C. (2016). El régimen de Pinochet. Santiago, Chile: Taurus.

Jara, D. y Aguilera, C. (2017). Pasados inquietos. Los desafíos de la memoria pública de los perpetradores de violaciones de DD.HH. y crímenes de lesa humanidad en Argentina y Alemania. Santiago, Chile: Museo de la Memoria y los Derechos Humanos.

Joignant, A. (2018, mayo 31). Pinochet en la historia. La Segunda. Disponible en: http://impresa.lasegunda.com/2018/05/31/A/VC3D4KRT

Lazzara, M. J. (2018). Civil Obedience. Complicity and Complacency in Chile since Pinochet. Madison, United States: The University of Wisconsin Press.

Lavín, J. (1987). Chile: revolución silenciosa. Santiago, Chile: Zig-Zag.

Martínez de Pisón, J. (1996). Libertad y Estado en la teoría neoliberal. Anuario de Filosofía del Derecho XIII, 241-264.

Moulian, T. (1997). Chile actual: anatomía de un mito. Santiago, Chile: Lom Ediciones.

Museo Histórico Nacional (2018). Hijos de la Libertad. 200 años de Independencia (Santiago: Servicio Nacional del Patrimonio Cultural). En línea: https://www.mhn.gob.cl/618/articles-85161_archivo_01.pdf

Passmore, L. (2017). The War inside Chile's Barracks. Remembering Military Service under Pinochet. Madison, United States: The University of Wisconsin Press.

Pinochet, A. (1973, septiembre-octubre). Discurso pronunciado por el señor Presidente de la Junta de Gobierno, General de Ejército don Augusto Pinochet Ugarte, al cumplirse un mes desde la fecha de constitución de la Junta de Gobierno, en Antecedentes histórico-jurídicos relacionados con el cambio de gobierno en Chile. Revista de Derecho, Jurisprudencia, y Ciencias Sociales, Tomo LXX, 7-8.

Pinochet, A. (2001 [1974]). Declaración de Principios del Gobierno de Chile. En Correa, S.; Figueroa, C.; Jocelyn-Holt, A; Rolle, C.; Vicuña, M. (comps.) 
Documentos del siglo XX chileno (pp. 428-444). Santiago, Chile: Editorial Sudamericana.

Pinochet, A. (1983). Pinochet: patria y democracia. Santiago, Chile: Editorial Andrés Bello.

Ponce, J.I.; Pérez, A. y Acevedo, N. (comps.) (2018). Transiciones. Perspectivas historiográficas sobre la post-dictadura chilena, 1988-2018. Santiago, Chile: Editorial América en Movimiento.

Rebolledo, J. (2014). La danza de los cuervos: el destino final de los detenidos desaparecidos. Santiago, Chile: Ceibo Ediciones.

Rousso, H. (2018 [2012]). La última catástrofe. La historia, el presente, lo contemporáneo (Trad. de Denise Bard). Santiago, Chile: Editorial Universitaria, Centro de Investigaciones Diego Barros Arana.

Ruiz, C. (2015). De nuevo la sociedad. Santiago, Chile: Lom Ediciones.

Taylor, M. (2006). From Pinochet to the "Third Way". Neoliberalism and Social Transformation in Chile. London, United Kingdom: Pluto Press.

Traverso, E. (2012 [2011]). La historia como campo de batalla. Interpretar las violencias del siglo XX. Buenos Aires, Argentina: Fondo de Cultura Económica.

Vicuña, M. (2008). El bestiario del historiador: las biografías de 'monstruos' de Benjamín Vicuña Mackenna y la identidad liberal como bien en disputa. Historia I(41), 189-214.

Zamora, D. (2019). Cómo el neoliberalismo reinventó la democracia. Entrevista a Niklas Olsen. Nueva Sociedad 282, 148-155. 